\title{
Comparison of 30-day case-fatality rate between dialysis and transplant Covid-19 patients: a propensity score matched cohort study
}

\author{
Tainá Veras de Sandes-Freitas ${ }^{1,2,3}$ (1) - Luís Gustavo Modelli de Andrade ${ }^{4}(1) \cdot$ Lucio Roberto Requião Moura $^{5,6,7}$ (1) . \\ Marina Pontello Cristelli ${ }^{5}$. José Osmar Medina-Pestana ${ }^{5,6}$ - Jocemir Ronaldo Lugon ${ }^{8}$ (i) $\cdot$ Ricardo Sesso $^{6}$ (i) $\cdot$ For \\ the Brazilian Covid-19 Dialysis Investigators and the Covid-19-KT Brazilian Study Group
}

Received: 21 July 2021 / Accepted: 17 September 2021 / Published online: 22 October 2021

(C) Italian Society of Nephrology 2021

\begin{abstract}
Background and objectives Patients undergoing kidney replacement therapies (KRTs) have a poor prognosis after Covid-19 infection. Few studies have compared the outcomes of such patients in the different KRT modalities. This study aimed to analyze the 30-day Covid-19-associated case-fatality rate of dialysis and kidney transplant patients.

Methods Retrospective cohort study analyzing data from patients with confirmed Covid-19 between Mar/20 and Jan/21 included in two multicenter studies, the Brazilian Covid-19 Dialysis Study (Dialysis group, $n=703$ ) and the Covid-19-KT Brazilian Study (Transplant group, $n=1907$ ). To assess the risk factors for death, adjusted Cox hazards models were used. A sensitivity analysis was performed using a propensity score analysis to match the groups ( $n=587$ patients in each group). Results A higher percentage of transplant patients required hospitalization ( 68 vs. $51 \%, p<0.001)$, intensive care (37 vs. $30 \%, p=0.023$ ), and invasive mechanical ventilation ( $28 \mathrm{vs.} 22 \%, p=0.035)$. Multivariate analysis of the before-matching sample showed that subjects in the transplant group were at a lower death risk at baseline (HR $\left.{ }_{0.38} 0.56_{0.85}\right)$. However, they showed higher risk over time ( $\left.\mathrm{HR}_{1.03} 1.06_{1.09}\right)$. Kaplan-Meier analysis after propensity score matching confirmed the inferior 30 -day cumulative survival in the transplant recipients ( 83 vs. $78 \%, p=0.0014$ ).

Conclusion Both transplant and dialysis patients have high 30-day case-fatality rates after a Covid-19 diagnosis. Despite lower death risk at baseline, transplant patients have an increased death risk of $6 \%$ per day than dialysis patients.
\end{abstract}

Keywords COVID-19 $\cdot$ Renal dialysis · Kidney transplantation $\cdot$ Propensity score

Tainá Veras de Sandes-Freitas and Luís Gustavo Modelli de Andrade are both first authors.

Jocemir Ronaldo Lugon and Ricardo Sesso are both senior authors.

For the Brazilian Covid-19 Dialysis investigators and the Covid19-KT Brazilian Study Group updated in Acknowledgments.

Lucio Roberto Requião Moura

lucio.requiao@gmail.com

1 Programa de Pós-Graduação Em Ciências Médicas, Departamento de Medicina Clínica, Faculdade de Medicina, Universidade Federal Do Ceará, Fortaleza, CE, Brazil

2 Hospital Universitário Walter Cantídio, Fortaleza, CE, Brazil

3 Hospital Geral de Fortaleza, Fortaleza, CE, Brazil

4 Departamento de Medicina Interna, Universidade Estadual Paulista-UNESP, Botucatu, SP, Brazil

\section{Introduction}

As of June 2021, Brazil was one of the most affected countries by the Covid-19 pandemic, with more than 18 million confirmed cases and more than 510 thousand deaths, corresponding to an overall case-fatality rate of $2.8 \%$ [1]. The

5 Hospital Do Rim, Fundação Oswaldo Ramos, São Paulo, SP, Brazil

6 Departamento de Medicina, Disciplina de Nefrologia, Universidade Federal de São Paulo. Rua Botucatu, 740, São Paulo, SP 04023-062, Brazil

7 Unidade de Transplante Renal, Hospital Israelita Albert Einstein, São Paulo, SP, Brazil

8 Departamento de Medicina, Divisão de Nefrologia, Universidade Federal Fluminense, Rio de Janeiro, RJ, Brazil 
Brazilian response to the pandemic has been criticized due to the lack of appropriate and timely public health measures and vaccination roll-out [2].

People under kidney replacement therapy (KRT) are at higher risk for more severe Covid-19, with a case-fatality rate ranging from 20 to $30 \%$ [3-7]. Underlying chronic kidney disease, immunosuppressive status, and the frequent coexistence of other medical conditions may explain these findings. In this context, Brazil is in a highly vulnerable situation since it is the world's third country with regard to patients on chronic dialysis and the second for absolute number of kidney transplants (KT). By July 2020, the estimated total number of patients on dialysis was 144,779 , and about 63,000 had a functioning kidney graft $[8,9]$.

There are few comparative studies on the impact of Covid-19 on the different modalities of KRT. The European Renal Association Registry, including 3285 Covid19 patients on dialysis and $1013 \mathrm{KT}$ recipients, found an increased risk of death in transplant recipients versus matched dialysis patients. However, this was not the study's primary objective, and estimates were not adjusted for several potential confounders [4]. Recently, the ERACODA registry reported an increased risk of mortality in transplant compared with dialysis [10]. However, ethnicity, practices, and Covid-19 care worldwide are not uniform and may lead to differences in outcomes. Therefore, assessing the comparison of the death risk in patients undergoing KRT is of interest to understand the impact of Covid-19 in different parts of the world.

This study aims to compare the 30-day case-fatality rate of dialysis and transplant patients in Brazil after a diagnosis of Covid-19.

\section{Methods}

\section{Population and setting}

This was a retrospective analysis using data from two multicenter Brazilian studies: data on dialysis patients were obtained from the Brazilian Covid-19 Dialysis Study group, comprising 65 dialysis units all over the country [11]; data on KT patients were extracted from the Covid-19-KT Brazilian Study (NCT 04494776), including data from 43 transplant sites [12].

Eligible participants for this analysis were CKD-5 patients on dialysis or who had undergone KT, aged more than 18 years, who had Covid-19-related signs and symptoms and had SARS-CoV-2 detected by reverse-transcription polymerase chain reaction (RT-PCR) in a nasopharynx sample between 03/01/2020 and 01/31/2021. Patients were followed-up for 30 days after the diagnosis or until death.
Recipients of combined KT and those with missing data regarding 30-day survival were excluded.

\section{Variables}

The variables of interest for all patients were: Site's Brazilian geographic region (South, North, Northeast, Midwest, or Southeast); demographics (gender, age, ethnicity, body mass index); comorbidities (diabetes, cardiovascular disease, hypertension, HIV seropositivity, chronic liver disease, chronic pulmonary disease, neurological disease, peripheral arterial disease, current or previous neoplasia, use of reninangiotensin system inhibitors, smoking); and Covid-19 clinical manifestations (fever, cough, dyspnea, fatigue, myalgia, gastrointestinal symptoms, and sensory disturbance). Gastrointestinal symptoms considered were diarrhea, nausea, vomiting, epigastric or abdominal pain, and dyspepsia.

In dialysis patients, we also evaluated the dialysis modality (hemodialysis or peritoneal dialysis), and time on dialysis. In transplant patients, we accessed information on donor source, time after KT, immunosuppressive regimen at diagnosis, and baseline serum creatinine.

Patients with Covid-19 were allocated to home care or admitted to the hospital for clinical management. The initial and subsequent allocation, clinical management and the immunosuppressive management during the disease were at the discretion of the assistant physicians.

\section{Outcomes}

The primary outcome was the case-fatality rate within 30 days of Covid-19 diagnosis. The rates of hospitalization, admission to intensive care unit, and invasive mechanical ventilation were also assessed.

\section{Statistics}

\section{Missing data}

We prior stipulated an approach to imputation for variables with more than $15 \%$ missing data. If more than $15 \%$ missing data were found, we planned to use Multivariate Imputation by Chained Equations. Because most parameters had less than $10 \%$ of missing data, the listwise deletion approach was used. The data pattern suggested missing at random. Missing data were included in demographic tables.

\section{Univariate comparations}

All continuous data were non-normally distributed and were presented as median and interquartile range and compared by the Mann-Whitney test. Categorical data were presented 
as absolute and/or percent frequency and compared by ChiSquare test.

\section{Before matching analysis}

To compare the 30-day mortality between dialysis and transplant patients, uni- and multivariate Cox models were fitted. We checked collinearity between independent variables with the variance inflation factor (VIF). We accepted the predictors with VIF values lower than 2 . The variables with a $p$ value below 0.10 in univariate analyses were included in the multivariate models. Given the previously demonstrated clinical relevance of body mass index in Covid-19 outcomes [13], we included such variable in the multivariable model regardless of its $p$ value in the univariate analysis.

The proportional hazards assumption was tested with the Schoenfeld residuals, and the Cox model did not reach proportionality. We then resorted to a time-dependent Cox model, using a time-by-covariate interaction and a linear function of time by group (dialysis/transplant). The model output for the group had two hazard ratios (HRs): baseline and over time (daily change). We used robust covariance to estimate the confidence interval of the Cox model. To assess survival, we used adjusted Cox hazards models survival curves. The main goal behind this function is to generate the expected survival curves calculated based on the Cox model, separately for subpopulations. The curves were calculated by the conditional method [14].

\section{Sensitivity analysis}

\section{Propensity score}

Propensity score matching was used to estimate the effect of the group accounting for confounding by the included covariates. Variables associated with Covid-19 prognosis were selected for the matching process: age, gender, ethnicity, body mass index, comorbidities, and geographic region of the transplant/dialysis site.

To reduce the number of categories, we assembled the Brazilian geographic regions according to the Human Development Index similarity, Northeast with Midwest and South with Southeast [15]. The North region had only four dialysis patients and no transplant cases and was excluded before the matching analysis. We used 1:1 nearest neighbor propensity score matching without replacement with a caliper of 0.1. Observations were discarded in both groups, and patients who could not be matched were deleted from the analyses. The propensity score was estimated using a logistic regression of the group (dialysis/transplant) on the covariates. After matching, all standardized mean differences for the covariates were below 0.1 , indicating adequate balance (Supplemental Figs. 1 and 2).
To estimate the treatment effect and its standard error after the match, we fitted a Cox model including the matching weights in the estimation. As this model violated the hazard proportionality, a time-dependent Cox model using the same approach described above was fitted [13]. To evaluate survival after the matching, Kaplan-Meier curves were used. Because the hazard was non-proportional, we used the Fleming-Harrington ( $\mathrm{rho}=1$ and lambda $=1)$ method to compare the groups [17]. Analyses were conducted using the R Statistical language (version 3.6.3; R Core Team, 2020).

\section{Results}

Between March 2020 and January 2021, 1097 dialysis patients were enrolled in the Brazilian Covid-19 Dialysis Study, and 2373 KT patients in the Covid-19-KT Brazilian Study $(n=3470)$. After exclusions, 2610 patients (703 in the dialysis group and 1907 in the KT group) remained in the study (Fig. 1).

There was a bimodal temporal distribution of Covid-19 cases in dialysis and transplant corresponding to the first and second Covid-19 waves in Brazil (Supplementary Fig. 3).

\section{Analysis before propensity score matching}

Baseline characteristics of the dialysis and transplant patients with Covid-19 before propensity score matching are shown in Table 1. Before matching, the dialysis group was older (median of 60 vs. 52 years, $p<0.001$ ), had a higher percentage of non-Caucasian ethnicity (46 vs. $38 \%$, $p<0.001$ ), diabetes ( 43 vs. $34 \%, p<0.001$ ), cardiovascular disease ( 23 vs. $12 \%, p<0.001$ ), hypertension ( 86 vs. $78 \%$, $p<0.001$ ), neurological disease (1.6 vs. $<0.1 \%, p<0.001$ ), and peripheral vascular disease ( 5 vs. $3 \%, p<0.001)$. In turn, the transplant group had higher median BMI (26.6 vs. $\left.25.0 \mathrm{~kg} / \mathrm{m}^{2}, p<0.001\right)$ and a higher percentage of current/ former smokers (22 vs. 9.7\%, $p<0.001)$.

In a multivariate Cox regression analysis, the factors associated with 30-day mortality were older age, diabetes, hypertension, cardiovascular disease, and chronic pulmonary disease (Supplementary Table 1).

At baseline, KT patients had a lower death risk (HR 0.56 $95 \%$ CI $0.38-0.85$ per day, $p=0.005$ ). However, survival curves intersected after two weeks, and then KT patients turned out to have higher risk of dying (HR 1.06, 95\% CI $1.03-1.09, p<0.001$ per day) (Fig. 2a, Supplementary Table 1). The HR over time can be predicted by the equation: $\mathrm{HR}=\exp (-0.56+(0.06 \times$ time in days $))$. A further model adjusted to initial symptoms showed a similar baseline HR of 0.66 [95\% CI 0.44-0.99], $p<0.001$ and an HR over time of 1.06 [95\% CI 1.02-1.09], $p<0.001$ ) (Supplemental Table 2). 
Fig. 1 Flow diagram showing the selection process of the dialysis and transplant patients included in the study. RT-PCR, reverse-transcription polymerase chain reaction
Dialysis and kidney transplant patients with confirmed Covid-19 included in

Brazilian Covid-19 Dialysis Registry and Covid-19 KT Brazilian Study between March 1st, 2020 and January 31th, 2021

Dialysis group $n=1,097 \quad$ Transplant group $n=2,373$

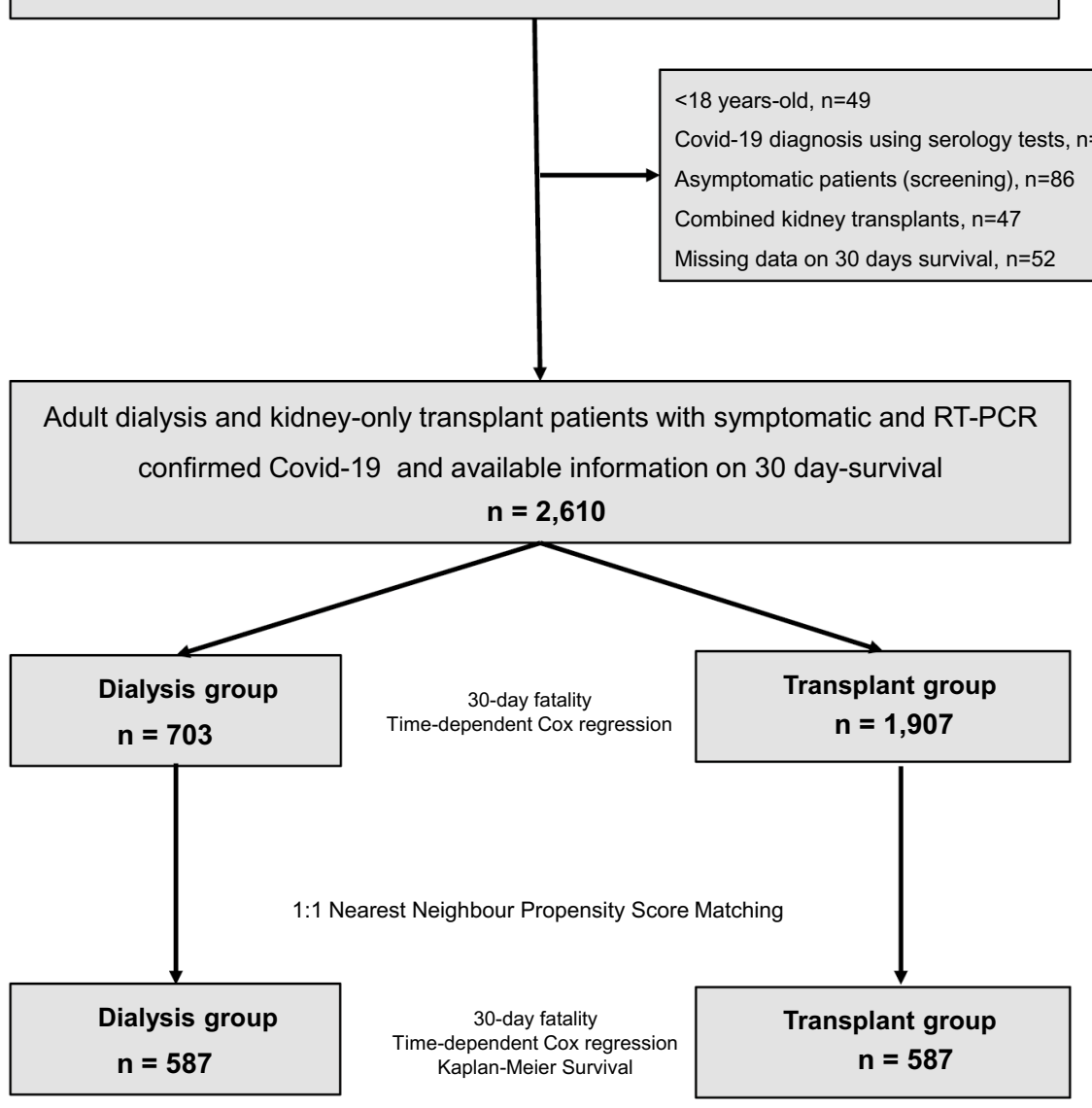

\section{Analysis after propensity score matching}

After propensity score matching, a sample of 587 dialysis and 587 transplant patients was obtained. Baseline characteristics after the matching were similar between the groups (Table 1).

Regarding the initial clinical picture, patients in the dialysis group appeared to have a more severe presentation, with a higher frequency of cough (60 vs. 52\%, $p=0.014)$, dyspnea (43 vs. $35 \%, p=0.002)$, fatigue $(35$ vs. $25 \%, p<0.001$ ), and sensory disturbance (4.4 vs. $1.7 \%$, $p=0.007)$. Transplanted patients, in turn, had a higher prevalence of myalgia (40 vs. $30 \%, p<0.001$ ) and gastrointestinal symptoms (32 vs. $21 \%, p<0.001)$ (Table 1$)$.

Despite the milder clinical presentation, the transplant group had worse outcomes, with a higher need for hospitalization (68 vs. $51 \%, p<0.001$ ), admission to intensive care unit (37 vs. 30\%, $p=0.023$ ), and invasive mechanical ventilation ( 28 vs. $22 \%, p=0.035$ ), and a trend for higher 30 -day mortality in a contingency table analysis (22 vs. $17 \%, p=0.06$, Table 2).

The survival pattern observed in the pre-matching population persisted after matching. The 30-day fatality risk of transplant versus dialysis patients using a timedependent Cox model showed a baseline HR of 0.63 [95\% CI 0.37-1.07], $p=0.087$. Survival curves crossed after 15 days and HR over time was 1.06 [95\% CI 1.02-1.10] per day, $p=0.004$. The HR over time can be predicted by the equation: $\mathrm{HR}=\exp (-0.47+(0.06 \times$ time in days $))$. Kaplan-Meier analysis showed a 30-day cumulative survival of $83 \%$ [95\% CI 80-85\%] in dialysis and 78\% [95\% CI 75-82\%] in transplant patients, $p=0.0014$, Fleming-Harrington test (Fig. 2b, Supplemental Table 3). 
Table 1 Baseline characteristics and clinical presentation of dialysis and transplant patients with COVID-19 before and after propensity score matching

\begin{tabular}{|c|c|c|c|c|c|c|c|}
\hline & & \multicolumn{3}{|l|}{ Before matching } & \multicolumn{3}{|l|}{ After matching } \\
\hline & & $\begin{array}{l}\text { Dialysis } \\
N=703\end{array}$ & $\begin{array}{l}\text { Transplant } \\
N=1907\end{array}$ & $p$ value & $\begin{array}{l}\text { Dialysis } \\
N=587\end{array}$ & $\begin{array}{l}\text { Transplant } \\
N=587\end{array}$ & $p$ value \\
\hline \multirow{33}{*}{$\begin{array}{l}\text { Baseline demographic } \\
\text { and clinical charac- } \\
\text { teristics }\end{array}$} & Region, $n(\%)$ & & & $<0.001$ & & & 0.584 \\
\hline & $\begin{array}{l}\text { Northeast and Mid- } \\
\text { west }\end{array}$ & $196(28)$ & $242(13)$ & & $144(25)$ & $136(23)$ & \\
\hline & South and Southeast & $503(72)$ & $1665(87)$ & & $442(75)$ & $450(77)$ & \\
\hline & $\begin{array}{l}\text { Age (years), median } \\
\text { (IQR) }\end{array}$ & $60(48-70)$ & $52(42-61)$ & $<0.001$ & $58(45-67)$ & $55(45-66)$ & 0.082 \\
\hline & $\begin{array}{l}\text { Age range in years, } n \\
(\%)\end{array}$ & & & $<0.001$ & & & 0.742 \\
\hline & $18-44$ & $154(22)$ & $634(33)$ & & $149(25)$ & $160(27)$ & \\
\hline & $45-65$ & $290(41)$ & $1013(53)$ & & $272(46)$ & $269(46)$ & \\
\hline & $>65$ & $259(37)$ & $260(14)$ & & $166(28)$ & $158(27)$ & \\
\hline & Gender, $n(\%)$ & & & 0.576 & & & 0.839 \\
\hline & Female & $278(40)$ & $734(39)$ & & $234(40)$ & $237(40)$ & \\
\hline & Male & $422(60)$ & $1172(61)$ & & $351(60)$ & $349(60)$ & \\
\hline & Missing & $3(0.4)$ & $1(<0.1)$ & & $2(0.3)$ & $1(0.2)$ & \\
\hline & Ethnicity, $n(\%)$ & & & $<0.001$ & & & 0.725 \\
\hline & Caucasian/White & $374(54)$ & $1178(62)$ & & $323(55)$ & $317(54)$ & \\
\hline & Non-Caucasian/White & $316(46)$ & $707(38)$ & & $263(45)$ & $269(46)$ & \\
\hline & Missing & $13(1.9)$ & $22(1.1)$ & & $1(0.2)$ & $1(0.2)$ & \\
\hline & $\begin{array}{l}\text { BMI }\left(\mathrm{Kg} / \mathrm{m}^{2}\right), \text { median } \\
\quad(\mathrm{IQR})\end{array}$ & $25.0(22.1-28.4)$ & $26.6(23.7-29.9)$ & $<0.001$ & $25.5(22.3-28.8)$ & $26.0(23.0-29.0)$ & 0.172 \\
\hline & Missing & $7(1.0)$ & $41(2.1)$ & & $0(0)$ & $0(0)$ & \\
\hline & BMI category, $n(\%)$ & & & 0.002 & & & 0.105 \\
\hline & $\leq 30 \mathrm{~kg} / \mathrm{m}^{2}$ & $566(81)$ & $1410(76)$ & & $466(79)$ & $488(83)$ & \\
\hline & $>30 \mathrm{~kg} / \mathrm{m}^{2}$ & $130(19)$ & $456(24)$ & & $121(21)$ & $99(17)$ & \\
\hline & Missing & $7(1.0)$ & $41(2.1)$ & & $0(0)$ & $0(0)$ & \\
\hline & Comorbidities, $n(\%)$ & & & & & & \\
\hline & Diabetes & $300(43)$ & $652(34)$ & $<0.001$ & $228(39)$ & $228(39)$ & 0.998 \\
\hline & Cardiovascular disease & $164(23)$ & $226(12)$ & $<0.001$ & $108(18)$ & $110(19)$ & 0.887 \\
\hline & Hypertension & $605(86)$ & $1490(78)$ & $<0.001$ & $500(85)$ & $493(84)$ & 0.575 \\
\hline & HIV seropositivity & $5(0.7)$ & $11(0.6)$ & 0.778 & $4(0.7)$ & $4(0.7)$ & 0.999 \\
\hline & Chronic liver disease & $15(2.1)$ & $56(2.9)$ & 0.263 & $12(2.0)$ & $8(1.4)$ & 0.377 \\
\hline & $\begin{array}{l}\text { Chronic pulmonary } \\
\text { disease }\end{array}$ & $28(4.0)$ & $57(3.0)$ & 0.204 & $18(3.1)$ & $18(3.1)$ & 0.999 \\
\hline & Neurological disease & $11(1.6)$ & $1(<0.1)$ & $<0.001$ & $1(0.2)$ & $0(0)$ & 0.999 \\
\hline & $\begin{array}{l}\text { Peripheral vascular } \\
\text { disease }\end{array}$ & $35(5.0)$ & $6(0.3)$ & $<0.001$ & $12(2.0)$ & $6(1.0)$ & 0.152 \\
\hline & Neoplasia & $25(3.6)$ & $94(4.9)$ & 0.136 & $22(3.7)$ & $22(3.7)$ & 0.999 \\
\hline & RAS blockage, $n(\%)$ & $296(46)$ & $625(33)$ & $<0.001$ & $241(44)$ & $262(46)$ & 0.384 \\
\hline
\end{tabular}


Table 1 (continued)

\begin{tabular}{|c|c|c|c|c|c|c|}
\hline & \multicolumn{3}{|c|}{ Before matching } & \multicolumn{3}{|l|}{ After matching } \\
\hline & $\begin{array}{l}\text { Dialysis } \\
N=703\end{array}$ & $\begin{array}{l}\text { Transplant } \\
N=1907\end{array}$ & $p$ value & $\begin{array}{l}\text { Dialysis } \\
N=587\end{array}$ & $\begin{array}{l}\text { Transplant } \\
N=587\end{array}$ & $p$ value \\
\hline Missing & $55(7.8)$ & $31(1.6)$ & & $33(5.6)$ & $19(3.2)$ & \\
\hline Smoking, $n(\%)$ & & & & & & \\
\hline Current & $11(1.6)$ & $47(3.0)$ & 0.046 & $10(1.7)$ & $8(1.4)$ & 0.653 \\
\hline Former & $58(8.3)$ & 305 (19) & $<0.001$ & $56(9.6)$ & $53(9.1)$ & 0.782 \\
\hline Current or former & $68(9.7)$ & $352(22)$ & $<0.001$ & $65(11)$ & $61(10)$ & 0.733 \\
\hline Missing & $0(0)$ & 336 (17.6) & & $0(0)$ & $3(0.5)$ & \\
\hline Dialysis modality, $n(\%)$ & & & NA & & & NA \\
\hline Hemodialysis & $690(98)$ & NA & & $575(98)$ & NA & \\
\hline Peritoneal & $12(1.7)$ & NA & & $10(1.7)$ & NA & \\
\hline Missing & $1(0.1)$ & NA & & $1(0.2)$ & NA & \\
\hline $\begin{array}{l}\text { Time on dialysis (years), } \\
\text { median (IQR) }\end{array}$ & $2.5(1.0-5.3)$ & NA & NA & $2.5(1.0-5.4)$ & NA & \\
\hline Missing & $243(34.6)$ & NA & & 198 & & NA \\
\hline $\begin{array}{l}\text { Time after KT (years), } \\
\text { median (IQR) }\end{array}$ & NA & $6.0(2.3-10.9)$ & NA & NA & $6.1(2.3-10.2)$ & \\
\hline Missing & NA & $4(0.2)$ & & NA & $2(0.3)$ & \\
\hline Donor source, $n(\%)$ & & & NA & & & NA \\
\hline Deceased & NA & $1253(66)$ & & NA & $403(69)$ & \\
\hline Living & NA & $652(34)$ & & NA & $182(31)$ & \\
\hline Missing & NA & $2(0.1)$ & & NA & $1(0.2)$ & \\
\hline $\begin{array}{l}\text { IS regimen at diagnosis, } \\
n(\%)\end{array}$ & & & NA & & & NA \\
\hline TAC-MPA & NA & $1069(56)$ & & NA & $322(55)$ & \\
\hline TAC-AZA & NA & $241(13)$ & & NA & $73(12)$ & \\
\hline TAC-mTORi & NA & $156(8.2)$ & & NA & $53(9.1)$ & \\
\hline CSA-AZA & NA & $80(4.2)$ & & NA & $21(3.6)$ & \\
\hline CSA-MPA & NA & $83(4.4)$ & & NA & $20(3.4)$ & \\
\hline mTORi-MPA & NA & $76(4.0)$ & & NA & $34(5.8)$ & \\
\hline Other & NA & $194(10)$ & & NA & $62(11)$ & \\
\hline Missing & NA & $8(0.4)$ & & NA & $2(0.3)$ & \\
\hline $\begin{array}{l}\text { Steroid-based regimen, } \\
n(\%)\end{array}$ & NA & $1789(94)$ & NA & NA & 549 (94) & NA \\
\hline Missing & NA & $3(0.2)$ & & NA & $0(0)$ & \\
\hline $\begin{array}{l}\text { Baseline } \mathrm{sCr}(\mathrm{mg} / \mathrm{dL}), \\
\text { median (IQR) }\end{array}$ & NA & $1.50(1.20-2.00)$ & NA & NA & $1.5(1.2-2.0)$ & NA \\
\hline
\end{tabular}


Table 1 (continued)

\begin{tabular}{|c|c|c|c|c|c|c|c|}
\hline & & \multicolumn{3}{|c|}{ Before matching } & \multicolumn{3}{|c|}{ After matching } \\
\hline & & $\begin{array}{l}\text { Dialysis } \\
N=703\end{array}$ & $\begin{array}{l}\text { Transplant } \\
N=1907\end{array}$ & $p$ value & $\begin{array}{l}\text { Dialysis } \\
N=587\end{array}$ & $\begin{array}{l}\text { Transplant } \\
N=587\end{array}$ & $p$ value \\
\hline \multirow{7}{*}{$\begin{array}{l}\text { Signs/ symptoms at } \\
\text { diagnosis }\end{array}$} & Fever & $458(65)$ & $1092(57)$ & $<0.001$ & $374(64)$ & $342(58)$ & 0.056 \\
\hline & Cough & $421(60)$ & $1027(54)$ & 0.006 & $350(60)$ & $308(52)$ & 0.014 \\
\hline & Dyspnea & $321(46)$ & $662(35)$ & $<0.001$ & $255(43)$ & $203(35)$ & 0.002 \\
\hline & Fatigue & $249(35)$ & $424(22)$ & $<0.001$ & $206(35)$ & $146(25)$ & $<0.001$ \\
\hline & Myalgia & $205(29)$ & $798(42)$ & $<0.001$ & $174(30)$ & $232(40)$ & $<0.001$ \\
\hline & $\begin{array}{l}\text { Gastrointestinal symp- } \\
\text { toms }\end{array}$ & $149(21)$ & $658(35)$ & $<0.001$ & $126(21)$ & $188(32)$ & $<0.001$ \\
\hline & Sensory disturbance & $39(5.5)$ & $20(1.0)$ & $<0.001$ & $26(4.4)$ & $10(1.7)$ & 0.007 \\
\hline
\end{tabular}

$B M I$ body mass index, RAS Renin-angiotensin system, KT kidney transplantation, TAC tacrolimus, MPA mycophenolate, $m T O R i$ mammalian target of rapamycin inhibitor, $C S A$ cyclosporine, $A Z A$ azathioprine, $S C r$ serum creatinine, $I S$ immunosuppression, $N A$ not applicable or nonavailable

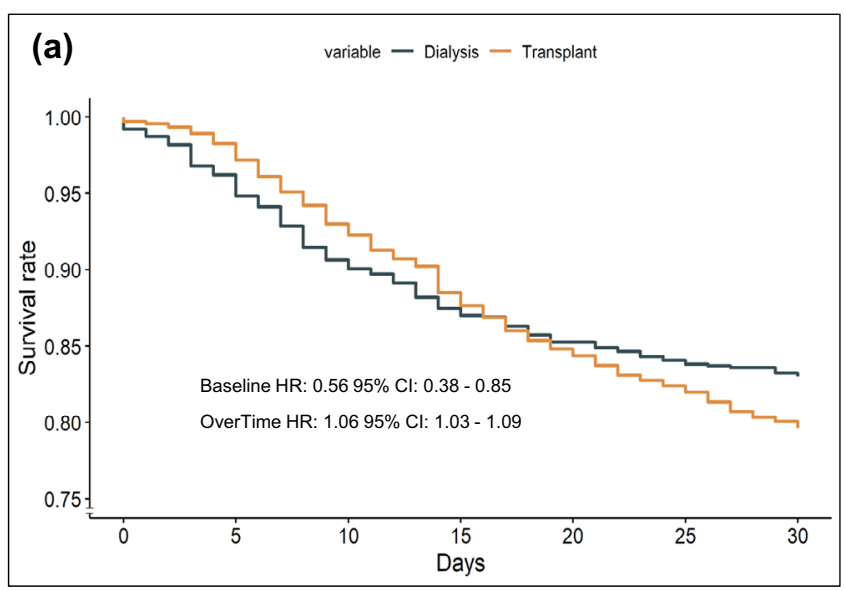

$$
\begin{aligned}
& \text { Number at Risk } \\
& \text { Dialysis } 703 \\
& \text { Transplant } 1907
\end{aligned}
$$

618
1788
10

Fig. 2 a 30-day survival rate (adjusted Cox Hazards Model) for dialysis and kidney transplant patients with Covid-19 before matching. b 30-day Kaplan-Meier survival curves for dialysis and kidney transplant patients with Covid-19 after matching (sensitivity analysis). a The reference group was dialysis, and hazard ratio (HR) refers to transplant patients. The baseline HR refers to time zero and overtime

\section{Subgroup analysis after matching}

After matching, 30-day survival probabilities were compared according to subgroups, fitted by age, presence of diabetes mellitus, and BMI, as depicted in Table 2 and Supplementary Figs. 4, 5, and 6. The survival curve by age categories showed that in the age group from 18 to 44 years the survival probabilities in dialysis and transplant

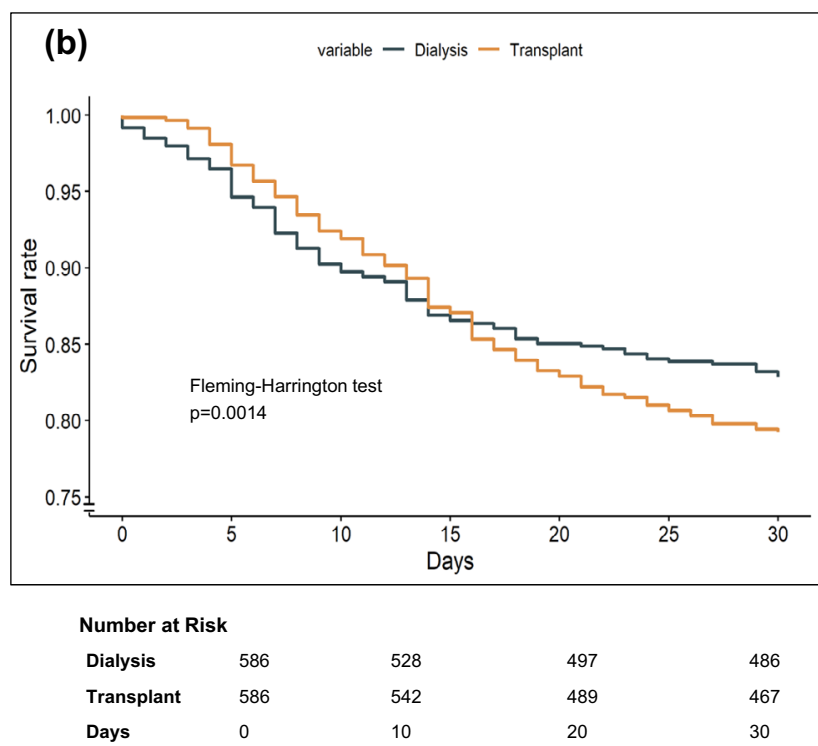

refers to the daily risk. Estimates were obtained with Cox hazards models adjusted for age, diabetes, hypertension, cardiovascular disease, and chronic pulmonary disease; curves were constructed with the conditional method. b The Fleming-Harrington test was used to calculate the $p$ value due to the non-proportionality of the risks

at 30 days were, respectively, $89 \%$ [95\% CI 83-94\%] and 94\% [95\% CI 90-97\%], $p=0.24$ (Supplementary Fig. 4a). In the age group between 45 and 65 years the corresponding survival probabilities were, respectively, $86 \%$ [95\% CI $81-89 \%$ ] and $79 \%$ [95\% CI 74-83\%], $p=0.015$ (Supplementary Fig. 4b). In the age group older than 65 years, the estimates were, respectively, $72 \%$ [95\% CI 65-79\%] and $62 \%$ [95\% CI 54-70\%], $p=0.0015$ (Supplementary Fig. 4c). 
Table 2 Outcomes of dialysis and transplant patients with Covid-19 before and after propensity score matching and 30-day survival probabilities according to subgroups after matching

\begin{tabular}{|c|c|c|c|}
\hline Outcomes & Dialysis & Transplant & $P$ value \\
\hline Before matching & $N=703$ & $N=1907$ & \\
\hline Hospitalization & $376(54)$ & $1240(65)$ & $<0.001$ \\
\hline Admission to intensive care unit & $237(34)$ & $655(35)$ & 0.689 \\
\hline Invasive mechanical ventilation & $174(25)$ & $474(25)$ & 0.959 \\
\hline 30-day case-fatality rate & $150(21)$ & $344(18)$ & 0.056 \\
\hline After matching & $N=587$ & $N=587$ & \\
\hline Hospitalization & $298(51)$ & $396(68)$ & $<0.001$ \\
\hline Admission to intensive care unit & $179(30)$ & $214(37)$ & 0.023 \\
\hline Invasive mechanical ventilation & $130(22)$ & $161(28)$ & 0.035 \\
\hline 30-day case-fatality rate & $102(17)$ & $127(22)$ & 0.066 \\
\hline $\begin{array}{l}\text { 30-day survival probabilities according to subgroups } \\
\text { (after matching) }\end{array}$ & $\begin{array}{l}\text { Dialysis } \\
N=587\end{array}$ & $\begin{array}{l}\text { Transplant } \\
N=587\end{array}$ & $P$ value \\
\hline \multicolumn{4}{|l|}{ Age (years) } \\
\hline $18-44$ & 89 [83-94] & 94 [90-97] & 0.24 \\
\hline $45-65$ & 86 [81-89] & 79 [74-83] & 0.015 \\
\hline$>65$ & $72[65-79]$ & $62[54-70]$ & 0.0015 \\
\hline \multicolumn{4}{|l|}{ Presence of diabetes } \\
\hline No & $85[72-83]$ & $86[83-90]$ & 0.42 \\
\hline Yes & 77 [82-89] & $66[60-72]$ & $<0.001$ \\
\hline \multicolumn{4}{|l|}{ BMI $\left(\mathrm{Kg} / \mathrm{m}^{2}\right)$} \\
\hline$<30$ & 84 [80-87] & 79 [75-82] & 0.002 \\
\hline$\geq 30$ & 77 [70-85] & 76 [68-84] & 0.31 \\
\hline
\end{tabular}

$B M I$ body mass index

The frequencies in percentages are presented in parenthesis

The $95 \%$ confidence intervals are presented in brackets

Among the patients with diabetes mellitus, the percent survival in dialysis and transplant recipients at 30 days was, respectively, 77\% [95\% CI 82-89\%] and 66\% [95\% CI $60-72 \%], p<0.001$ (Supplementary Fig. 5a). In nondiabetic ones, the corresponding figures were $85 \%$ [95\% CI 72-83\%] and 86\% [95\% CI 83-90\%], $p=0.42$, respectively (Supplementary Fig. 5b). When patients were grouped by BMI, those with more than $30 \mathrm{~kg} / \mathrm{m}^{2}$ had 30-day survival rates in dialysis and transplant of $77 \%$ [95\% CI 70-85\%] and 76\% [95\% CI 68-84\%], respectively, $p=0.31$ (Supplementary Fig. 6a). For individuals with BMI less than $30 \mathrm{~kg} / \mathrm{m}^{2}$, the corresponding estimates were $84 \%$ [95\% CI 80-87\%] and $79 \%$ [95\% CI 75-82\%], respectively, $p=0.002$ (Supplementary Fig. 6b).

\section{Discussion}

In this comparative multicenter cohort study, we observed an overall high 30-day Covid-19 case-fatality rate in dialysis and transplant patients ranging from 17 to $22 \%$. Numbers are about six times higher than the rate of $2.8 \%$ reported for the whole Brazilian population by June 25th [1].

This high mortality rate can, in part, be ascribed to the older age and the comorbidities commonly observed in kidney failure patients, as suggested in previous studies [5, 7, 18]. In addition, kidney dysfunction per se is associated with proinflammatory status and impairment of innate and adaptive response, impacting the outcomes of infectious diseases $[19,20]$.

In this analysis, mortality risk changed substantially along the 30 days. The initial mortality risk in the transplant group was lower than in the dialysis group, but over time transplant group mortality increased, catching up with the dialysis group after 15 days. Subsequently, the mortality risk of the transplant group overtook the dialysis group's risk and was $6 \%$ higher by each day of follow-up. This is in accordance with the findings of Jager et al. that showed higher 28-day mortality risk in transplant recipients [4]. Comparing cohorts of chronic dialysis and KT patients is a challenge because some variables, such as renal function and immunosuppressive drugs, cannot be 
matched. Also, KT recipients usually have a more favorable clinical profile than dialysis patients. In this study, we used a robust method with a propensity score matching analysis to adjust for baseline parameters and confounders. It should be underscored that such finding was seen either in the whole group using multivariate Cox analysis or in the sensitivity analysis after propensity score matching, reinforcing the robustness of the results.

The better survival favoring dialysis was even more remarkable in subgroups with age over 45 years, diabetes, and BMI lower than $30 \mathrm{~kg} / \mathrm{m}^{2}$. The impaired immune response associated with the immunosuppressive drugs in transplant patients may have accounted for their higher mortality risk [21]. Intriguingly, we noticed a higher risk of death for dialysis patients in the first days after diagnosis. We wonder if the finding could be partially accounted for by the higher frequency of respiratory symptoms at Covid-19 onset in dialysis patients. Accordingly, the transplant patients more commonly had gastrointestinal symptoms at diagnosis, a less life-threatening clinical finding. A high frequency of gastrointestinal symptoms at Covid19 onset in transplant patients had already been reported and interpreted as a possible superimposed effect of the immunosuppressive drugs [22]. Despite the differences in the symptom profile, a sensitivity analysis including initial symptoms as confounders did not modify our results.

Other aspects that may have played a role in the different mortality risks between groups and that could not be adequately explored in this study are the timing of Covid19 diagnosis and treatment interventions. Hemodialysis patients in this study were probably evaluated more frequently than transplant patients because of their thriceweekly visits for their in-center sessions, perhaps resulting in earlier Covid-19 testing and diagnosis. Unfortunately, data regarding the onset of Covid-19 symptoms to diagnosis were not available in the databases.

We used some non-traditional statistical methods in this study because the survival curves crossed, suggesting that the hazard ratio between the two groups had reversed, violating the assumption of risk proportionality. To account for the mortality risk changes over the 30 days, we used a time-dependent Cox regression in the crude analysis and the sensitivity analysis. To account for the non-proportionality, the Fleming-Harrington test [17], a weighted log-rank test used to detect late effects, substituted for the traditional log-rank.

In the present study, we addressed several important baseline confounding factors in the dialysis and transplant cohorts. Different from Jager et al.'s study [4], we had a more comprehensive adjustment for baseline variables and comorbidities. Unlike the ERACODA study [10], our population comprised a higher proportion of non-Caucasian patients (40 vs. $15 \%$ ) and did not include asymptomatic patients. Also, we carried out subgroup analysis and used propensity scores to match the two cohorts.

This study has some limitations. First, the sample of transplanted patients was greater than the sample of patients on chronic dialysis, contrary to the actual distribution of patients on KRT in the whole country. This feature may yield greater representativeness of the results for those transplanted. Furthermore, the comparison between dialysis techniques was not feasible given the small number of peritoneal dialysis patients studied. Second, we did not evaluate the time from the onset of symptoms to Covid-19 diagnosis, and the testing protocol for Covid-19 of the centers was not uniform. We excluded asymptomatic patients and those from dialysis and transplant centers that performed regular Covid19 screening tests to address these shortcomings, enrolling only cases whose tests were motivated by clinical suspicion of Covid-19. Third, some residual bias may have remained due to the lack of a thorough evaluation of confounders: KT cohort vintage is longer than that of the dialysis cohort; the overall time on KRT could not be matched between groups as the transplant recipients' database did not have the first dialysis date. Last, sampling bias is unlikely to have impacted our results since we used the two most extensive databases of Covid-19 in KRT in the country, and the geographic distribution of study participants was proportionally similar to that of all patients in the country. As the study's strengths, we highlight the high number of enrolled patients in both cohorts and the assessment of several confounding factors not evaluated in previous studies. Moreover, we resorted to a robust methodology to ensure adequate statistical analysis.

In conclusion, transplant and dialysis patients with Covid19 have a high 30-day case-fatality rate. The initial presentation of transplant patients in this sample was less severe, but their mortality risk, in the long run, was $6 \%$ higher per day in comparison to the dialysis patients. These results suggest that patients undergoing KRT need systematic surveillance with frequent Covid-19 testing, strict social and environmental precautionary measures, broad access to vaccination, attention to early symptoms, and prompt hospitalization if indicated.

Supplementary Information The online version contains supplementary material available at https://doi.org/10.1007/s40620-021-01172-1.

Acknowledgements Authors thank the investigators of the Brazilian Covid-19 dialysis study and the Covid-19-KT Brazilian Study.

Brazilian Covid-19 dialysis study investigators are the following: Adrian M. Borborema, Agostinho Filgueira Neto, Ailton C. Gallo, Almir A. Nascimento, Américo L. Cuvello Neto, Ana Katarina C. Lopes, Ana L. Gouveia, Ana Paula H. Mesquita, Anneliese R. Salmeron, Antonio A. Brito, Bruna Meneguelli, Carlos A. Caniello, Carmen A. Gomes, Cristiano V. Silva, Danielle A. Bazhuni, Eduardo A. Portioli, Edvaldo A. Costa Neto, Eli N. Silva, Eliana A. Monteiro, Evaldo G. Terra, Fabricio S. Fonseca, Fernanda S. Polacchini, 
Francisco Araujo, Franklin C. Barcellos, Gelzie S. Ennes, Gustavo A. Rigaud Neto, Henrique Gorla Neto, Homero C. Agra, Januário G. Roberto, João D. Simões, José C. Guilhen, José M. Obregón, José R. Boselli Jr., José R. Carvalho, Karina A. de Alcantara, Katia G. dos Santos, Leidiane F. Kurti, Lorena G. Oliveira, Luciana K. Batista, Lucíola R. Carneiro, Manif C. Jorge, Marcela M. Souto, Marcelly C. Rios, Marcelo A. Gonçalves, Marcelo X. Carrera, Marco A. Galvão, Maria E. Nardin, Maria F. Sarro, Maria T. Vannucchi, Marta A. Tormes, Maura Z. de Siqueira, Milene C. Gomes, Nelson Gushi, Nilo Hoefelmann, Nubia F. Moreira, Onesimo Domingos Filho, Patrícia S. Teixeira, Péricles Sarturi, Rafael S. Humel, Renan H. Emerick, Roberto Benvenutti, Roberto Rodrigues, Rodrigo R. Abrita, Rodrigo T. Belila, Rosangela Gomes, Rosilane F. Manfrim, Savina A. Bobbio, Sérgio M. Baltar, Shelle M. da Cunha, Simoni P. Melo, Suzana M. Melo, Tânia L. Costa, Vitor C. Vieira, Wellinton D. Silva.

Covid-19-KT Brazilian Study investigators are the following: Hélio Tedesco-Silva, Valter Garcia, Elizete Keitel, Claudia Maria Oliveira, Aline Alcântara, Ronaldo Esmeraldo, Mario Abbud-Filho, Ida Maria Charpiot, Alvaro Pacheco-Filho, Teresa Cristina Ferreira, Kátia Sousa, Roberto Ceratti Manfro, Alessandra Rosa Vicari, Kellen Micheline Costa, Tomás Pereira Júnior, Denise Simão, Maria Eduarda Coelho, Marilda Mazzali, Marcos Sousa, Gustavo Ferreira, Juliana Campos, Viviane Santana, Nicole Rocha, Anita Saldanha, Tania Martinez, Joao Egídio Romão Junior, Maria Regina Araújo, Irene Noronha, Sibele Braga, Luciane Deboni, Marcos Vieira, Elen Romao, Miguel MoysesNeto, Juliana Zanocco, Auro Claudino, Gustavo Guilherme Arimatea, Lívia Oliveira, Deise Carvalho, Tereza Matuck, Alexandre Bignelli, Silvia Hokazono, José Hermógenes Suassuna, Suzimar Rioja, Rafael Madeira, Sandra Vilaça, Carlos Calazans, Daniel Calazans, Patrícia Malafronte, Luiz Antônio Miorin, Larissa Andrade, Filipe de Aguiar, Fabiana de Carvalho, Karoline Martins, Hélady Pinheiro, Emiliana Sertório, André Pereira, David José Machado, Carolina Maria Pozzi, Leonardo Kroth, Lauro Vasconcellos, Rafael Maciel, Amanda Silva, Ana Paula Baptista, Pedro Augusto de Souza, Marcus Lasmar, Luciana Saber, Lilian Palma.

Author contributions All authors contributed to the study conception and design. Material preparation, data collection and analysis were performed by TVS-F, LGMA and LRRM. The first draft of the manuscript was written by TVS-F and all authors commented on previous versions of the manuscript. All authors read and approved the final manuscript.

Funding This research received no specific grant from any funding agency in the public, commercial, or not-for-profit sectors.

Availability of data and material The datasets generated and/or analyzed during the current study are available from the corresponding author on reasonable request.

Code availability Not applicable.

\section{Declarations}

Conflict of interest The authors have no conflicts of interest to declare that are relevant to the content of this article.

Ethical approval The study was approved by the IRB Invitare (identification number CAEE 45433121.9.0000.5045 and approval number 4.662.925).

Consent to participate All data were collected from previously anonymized and de-identified databases. Since it did not involve identifiable private information, a waiver of informed consent was granted.
Consent for publication Not applicable.

\section{References}

1. Brazil. Brazilian Ministry of Health. Painel de casos de doença pelo coronavírus 2019 (COVID-19) no Brasil pelo Ministério da Saúde. Coronavirus Brasil. [Online] Jun 24, 2021. https://covid. saude.gov.br/

2. Hallal PC (2021) SOS Brazil: science under attack. Lancet 397:373-374. https://doi.org/10.1016/S0140-6736(21)00141-0

3. Hilbrands LB, Duivenvoorden R, Vart P, Franssen CFM, Hemmelder MH, Jager KJ et al (2020) COVID-19-related mortality in kidney transplant and dialysis patients: results of the ERACODA collaboration. Nephrol Dial Transplant 35:1973-1983. https://doi. org/10.1093/ndt/gfaa261

4. Jager KJ, Kramer A, Chesnaye NC, Couchoud C, Sánchez-Álvarez JE, Garneata L et al (2020) Results from the ERA-EDTA Registry indicate a high mortality due to COVID-19 in dialysis patients and kidney transplant recipients across Europe. Kidney Int 98:1540 1548. https://doi.org/10.1016/j.kint.2020.09.006

5. Ng JH, Hirsch JS, Wanchoo R, Sachdeva M, Sakhiya V, Hong S, Consortium NC-RCatNNC-R et al (2020) Outcomes of patients with end-stage kidney disease hospitalized with COVID-19. Kidney Int 98:1530-1539. https://doi.org/10.1016/j.kint.2020.07.030

6. Pio-Abreu A, do Nascimento MM, Vieira MA, de Menezes Neves PDM, Lugon JR, Sesso R (2020) High mortality of CKD patients on hemodialysis with Covid-19 in Brazil. J Nephrol 33:875-877. https://doi.org/10.1007/s40620-020-00823-z

7. Ajaimy M, Liriano-Ward L, Graham JA, Akalin E (2021) Risks and benefits of kidney transplantation during the COVID-19 pandemic: transplant or not transplant? Kidney360 2(7):1179-1187. https://doi.org/10.34067/KID.0002532021

8. Brazil. Sociedade Brasileira de Nefrologia. Censo de Diálise da Sociedade Brasileira de Nefrologia 2020. [Online] (Cited: 31 Mar 2021). http://www.censo-sbn.org.br/censosAnteriores

9. Brazil. Associação Brasileira de Transplantes de Órgãos. Registro Brasileiro de Transplantes (RBT) 2020. Dimensionamento dos Transplantes no Brasil e em cada Estado (2013-2020). Ano XXVI No. 4. [Online] (Cited: 31 Mar 2021). http://abto.org.br

10. Goffin E, Candellier A, Vart P, Noordzij M, Arnol M, Covic A, ERACODA Collaborators et al (2021) COVID-19 related mortality in kidney transplant and hemodialysis patients: a comparative, prospective registry based study. Nephrol Dial Transplant. https:// doi.org/10.1093/ndt/gfab200

11. Lugon JR, Neves PDMM, Pio-Abreu A, do Nascimento MM, Sesso R, COVID-19 HD-Brazil Investigators (2021) Evaluation of central venous catheter and other risk factors for mortality in chronic hemodialysis patients with COVID-19 in Brazil. Int Urol Nephrol. https://doi.org/10.1007/s11255-021-02920-9

12. Requião-Moura LR, Sandes-Freitas TV, Viana LA, Cristelli MP, Andrade LGM, Garcia VD, COVID-19-KT Brazil (2021) High mortality among kidney transplant recipients diagnosed with coronavirus disease 2019: results from the Brazilian multicenter cohort study. PLoS ONE 16(7):0254822

13. Gao M, Piernas C, Astbury NM, Hippisley-Cox J, O’Rahilly S, Aveyard $\mathrm{P}$ et al (2021) Associations between body-mass index and COVID-19 severity in 6.9 million people in England: a prospective, community-based, cohort study. Lancet Diabetes Endocrinol 9:350-359. https://doi.org/10.1016/S2213-8587(21)00089-9

14. Therneau TM, Grambsch PM (2000) Modeling survival data: extending the Cox model. New York, USA: Springer-Verlag New York. https://doi.org/10.1007/978-1-4757-3294-8

15. Radboud University. Institute for Management Research. Global Data Web, 2003-2021. Human Development Indices (5.0). [Online] (Cited: 24 June 2021). https://globaldatalab.org/shdi/ 
16. Tolles J, Lewis RJ (2016) Time-to-event analysis. JAMA 315:1046-1047

17. Fleming TR, Harrington DP, Osullivan M (1987) Supremum Versions of the Log-Rank and Generalized Wilcoxon Statistics. J Am Stat Assoc 82(397):312-320

18. Williamson EJ, Walker AJ, Bhaskaran K, Bacon S, Bates C, Morton CE et al (2020) Factors associated with COVID-19-related death using OpenSAFELY. Nature 584(7821):430-436. https:// doi.org/10.1038/s41586-020-2521-4

19. Betjes MG (2013) Immune cell dysfunction and inflammation in end-stage renal disease. Nat Rev Nephrol 9:255-265. https://doi. org/10.1038/nrneph.2013.44

20. Cohen-Hagai K, Rozenberg I, Korzets Z, Zitman-Gal T, Einbinder Y, Benchetrit S (2016) Upper respiratory tract infection among dialysis patients. Isr Med Assoc J 18:557-560 (PMID: 28471606)
21. Vabret N, Britton GJ, Gruber C, Hegde S, Kim J, Kuksin M, Project SIR et al (2020) Immunology of COVID-19: current state of the science. Immunity 52:910-941. https://doi.org/10.1016/j. immuni.2020.05.002

22. Chaudhry ZS, Williams JD, Vahia A, Fadel R, Parraga Acosta T, Prashar R et al (2020) Clinical characteristics and outcomes of COVID-19 in solid organ transplant recipients: a case-control study. Am J Transplant 11:3051-3060. https://doi.org/10.1111/ ajt.16188

Publisher's Note Springer Nature remains neutral with regard to jurisdictional claims in published maps and institutional affiliations. 